\title{
How has the presidential election affected young Americans?
}

\author{
Melissa DeJonckheere ${ }^{1 *}$ (D) Andre Fisher ${ }^{2}$ and Tammy Chang ${ }^{1,3}$ (B)
}

\begin{abstract}
The 2016 presidential election season and subsequent political events have had physical and emotional impacts on youth. We collected qualitative insights from 14 to 24 year olds across the US related to these events over time. Openended probes were sent via text message at three time points before and after the 2016 presidential election. The majority of youth reported emotional stress during all three time points, and female participants were significantly more likely to experience emotional responses. White participants were more likely to report negative symptoms than their peers both pre-election and at 4-months post-election. While preliminary, the results indicate that feelings of stress, anxiety, and fear have persisted in the months following the election, particularly for young women. Additional research is needed to examine the long-term effects of political events on the emotional and physical health of youth.
\end{abstract}

Keywords: Adolescents, Mental health, Stress

\section{How has the presidential election affected young Americans?}

This past presidential election season and subsequent political events have affected many adults in the US both emotionally and physically [1], yet the impact on young people is not well understood. Research supports that current events, including election results, can impact health outcomes [2, 3]. For example, following the attacks on September 11th, health outcomes for Arab Americans worsened including lowered life expectancies and increased rates of premature births. Following the 2008 election, supporters of the losing candidate had higher cortisol responses than their peers. In both examples, political events worsened levels of stress and anxiety. In the months leading up to and following the 2016 presidential election, countless editorials and articles in popular media detailed the negative impact of the election season on US adults across political affiliations and states. To our knowledge, this phenomenon has not been adequately investigated in adolescents or young adults.

\footnotetext{
*Correspondence: mdejonck@med.umich.edu

1 Department of Family Medicine, University of Michigan, 1018 Fuller St, Ann Arbor, Ml 48104, USA

Full list of author information is available at the end of the article
}

Stress in youth is not benign and is linked to poor emotional and physical health effects. Specifically, stress is linked to cardiovascular disease, anxiety, depression, aggression, substance abuse, and behavioral problems in adolescence, as well as poor outcomes in adulthood [4-6]. The outcomes associated with stress are worsened when events are uncontrollable, like politics may feel to youth, leaving them feeling hopeless and unable to cope with adversity. As youth increasingly rely on social media for news and communication, the constant presence of information related to the election and subsequent political events may further impact the influence on youth.

We gather data from youth throughout the US every week via text messaging on a wide variety of healthrelated topics (see research protocol for description of ongoing study) [7]. Weekly topics reflect timely youthrelated policy issues or health concerns. Eligible participants (14-24 years of age, access to a phone with SMS capabilities) are recruited at community events and through social media, consented, and sent a link to an online demographic questionnaire. To understand youth experiences during and following the election, we used a longitudinal mixed methods design with three time points: 1-week pre-election, 2-weeks post-election, and 4-months post-election. Qualitative probes were developed to be open-ended and elicit narrative responses 
about participant beliefs, attitudes, and behaviors during the election season. Qualitative data were imported into MAXQDA software for analysis. Two researchers coded the data through a process of open coding and discrepancies were discussed until consensus was reached. Responses were then categorized as negative, neutral, or positive for quantitative descriptive analysis and compared using t-tests.

80 participants responded to at least one of the probes (pre-, post-election, or 4-months post-election) and had a mean age of $18.3(\mathrm{SD}=2.53$; Table 1$)$. Of those who completed the optional demographic survey $(n=69)$, nearly half were women (49\%). The majority identified as White (49\%; Black 15\%, Asian 14\%, Latino 4\%) and most had completed at least some high school $(49 \%)$ or some college (25\%). Evidenced by responses to open-ended probes, our sample included youth who supported candidates across the political spectrum.

Our results showed that a large proportion of youth were affected by the election, either emotionally $(86 \%$ pre-election; $71 \%$ post-election; $63 \% 4$-months post-election) and/or physically ( $20 \%$ pre-election; $19 \%$ post-election). Female participants were more likely to experience emotional responses at all three time points $(82 \%$ preelection; $80 \%$ post-election; $51 \%$ 4-months post-election; $\mathrm{p}<.05)$. Male participants reported emotional symptoms, but with less prevalence (61\% pre-election; $50 \%$ post-election; 32\% 4-months post-election). White participants were more likely to report negative symptoms than non-white participants both pre-election and 4 -months post-election $(\mathrm{p}<.05)$. For those that reported stress pre-election, negative symptoms remained 4-months after the election (see Table 2 for representative qualitative data).

The most commonly reported emotional responses throughout this time period were stress and anxiety ("It's contributed to my stress levels, which has made me feel more overwhelmed with my responsibilities"), worry ("I'm worried that [xenophobia] will continue to escalate after the election"), fear ("I am scared honestly, I don't know what is going to happen"), and disappointment ("It's upsetting that [the election] is such a mess"). Physical symptoms included feeling "tired," "drained," and "nauseous." One individual wrote that she was "not sleeping some nights" because of the election, while another described how hard it was to concentrate and do well in
Table 1 Participant demographics $\mathbf{n}=\mathbf{8 0}$

\begin{tabular}{lc}
\hline Characteristic & \\
\hline Age, M (SD) & $18.3(2.53)$ \\
Gender, $n$ (\%) & $39(49)$ \\
Female & $28(35)$ \\
Male & $2(3)$ \\
Genderfluid or trans & $11(14)$ \\
Unspecified & \\
Race and ethnicity, $n$ (\%) & $39(49)$ \\
White or Caucasian & $12(15)$ \\
Black or African American & $11(14)$ \\
Asian or Pacific Islander & $3(4)$ \\
Latino or Hispanic & $2(3)$ \\
American Indian or Alaska Native & $5(6)$ \\
Multiple races & $11(14)$ \\
Unspecified & \\
Education, highest level completed, $n(\%)$ & $31(39)$ \\
Some high school & $8(10)$ \\
High school graduate & $20(25)$ \\
Some college & $4(5)$ \\
College graduate & $2(3)$ \\
Some graduate school & $2(3)$ \\
Graduate degree & $13(16)$ \\
Unspecified & \\
\hline
\end{tabular}

school after the election. Stress affected vocal supporters of both candidates and vocal supporters of neither candidate. The small proportion who did not experience any emotional or physical symptoms across time points wrote that the election "hasn't affected" their daily lives or that they "don't worry about politics."

The election season and subsequent political events have already had emotional and physical repercussions on youth, making it an ongoing major public health concern that must be addressed. While preliminary and exploratory, the results of this longitudinal mixed methods study indicate that feelings of stress, anxiety, and fear have persisted in the months following the election, particularly for young women. We will continue to explore the impact of political events on youth in the US through ongoing quantitative and qualitative data collection. This research adds to the limited evidence that election results can impact emotional and physical health [1-3], though 


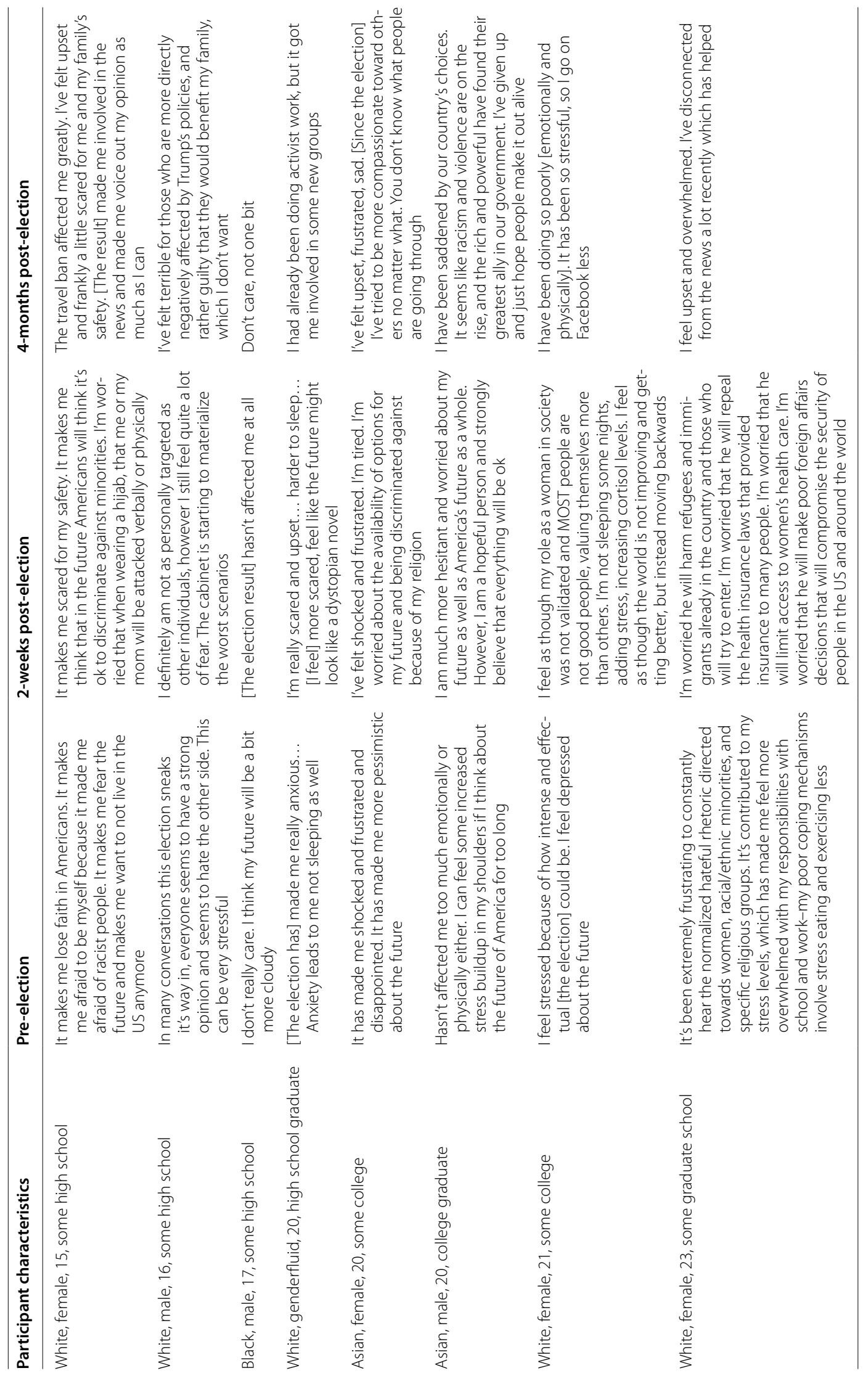


more research is needed to investigate this phenomenon in a representative sample of youth and to examine the long-term effects.

\section{Authors' contributions}

$\mathrm{MD}, \mathrm{AF}$ and $\mathrm{TC}$ contributed equally to the design, collection, analysis and interpretation of data as well as the writing of this commentary. All authors read and approved the final manuscript.

\section{Author details}

${ }^{1}$ Department of Family Medicine, University of Michigan, 1018 Fuller St, Ann Arbor, MI 48104, USA. ${ }^{2}$ University of Michigan, 500 S. State St, Ann Arbor, MI 48109, USA. ${ }^{3}$ Institute for Healthcare Policy and Innovation, University of Michigan, 2800 Plymouth Rd, Ann Arbor, Ml 48109, USA.

\section{Acknowledgements}

Not applicable.

\section{Competing interests}

The authors declare that they have no competing interests

\section{Availability of data and materials}

The datasets used and/or analyzed during the current study are available from the corresponding author on reasonable request.

\section{Consent for publication}

Not applicable.

\section{Ethics approval and consent to participate}

Ethics approval was obtained for this project by the University of Michigan Institutional Review Board (HUM00119982).

\section{Funding}

Department of Family Medicine, Michigan Medicine, MyVoice: Real-Time Text Messaging Polling to Give Adolescents a Voice, 9/1/16-8/31/17, \$25,000

This funder played no role in the following:

Design of the study. Collection, analysis, and interpretation of data. Writing the manuscript.
MCube, University of Michigan, MyVoice: Real-Time Text Messaging Polling to Give Adolescents a Voice, 12/01/15-04/29/17, \$60,000.

This funder played no role in the following:

Design of the study. Collection, analysis, and interpretation of data. Writing the manuscript.

\section{Publisher's Note}

Springer Nature remains neutral with regard to jurisdictional claims in published maps and institutional affiliations.

Received: 12 September 2017 Accepted: 15 January 2018

Published online: 13 February 2018

\section{References}

1. American Psychological Association. Stress in America: US Presidential election. http://www.apa.org/news/press/releases/2016/10/presidentialelection-stress.aspx. Accessed 12 Sept 2017.

2. Lauderdale DS. Birth outcomes for Arabic-named women in California before and after September 11. Demography. 2006;43:185-201.

3. Stanton SJ, Labar KS, Saini EK, Kuhn CM, Beehner JC. Stressful politics: voters' cortisol responses to the outcome of the 2008 United States presidential election. Psychoneuroendocrinology. 2010;35:768-74.

4. Grant KE, Compas BE, Thurm AE, McMahon SD, Gipson PY. Stressors and child and adolescent psychopathology: measurement issues and prospective effects. J Clin Child Adolesc Psychol. 2004;33:412-25.

5. Low CA, Salomon K, Matthews KA. Chronic life stress, cardiovascular reactivity, and subclinical cardiovascular disease in adolescents. Psychosom Med. 2009;71:927-31.

6. Romeo RD. The teenage brain: the stress response and the adolescent brain. Cur Dir Psychol Sci. 2013;22:140-5.

7. DeJonckheere M, Nichols LP, Moniz M, Sonneville KR, Zhao X, Vydiswaran VG, Guetterman TC, Chang T. MyVoice national text message survey of youth aged 14-24 years. JMIR Res Protoc. 2017;6(12):247. https://doi. org/10.2196/resprot.8502.

\section{Submit your next manuscript to BioMed Central and we will help you at every step:}

- We accept pre-submission inquiries

- Our selector tool helps you to find the most relevant journal

- We provide round the clock customer support

- Convenient online submission

- Thorough peer review

- Inclusion in PubMed and all major indexing services

- Maximum visibility for your research

Submit your manuscript at www.biomedcentral.com/submit 